\title{
Feeding preferences and performance of a marine isopod on seaweed hosts: cost of habitat specialization
}

\author{
Veijo Jormalainen $^{1, *}$, Tuija Honkanen ${ }^{1,2}$, Nina Heikkilä ${ }^{1}$ \\ ${ }^{1}$ Section of Ecology, Department of Biology, University of Turku, 20014 Turku, Finland \\ ${ }^{2}$ Southwest Finland Regional Environmental Centre, 20300 Turku, Finland
}

\begin{abstract}
The evolutionary hypotheses on plant-herbivore interaction assume that plant secondary compounds, such as the phlorotannins of brown algae, function as feeding deterrents for herbivores. We studied the effect of seaweed quality on the feeding preferences and performance of the isopod Idotea baltica. We offered I. baltica 6 species of algae, abundant in the Fucus vesiculosus belts where this mesograzer lives, in simultaneous preference tests. The tests were conducted both with natural algae and with artificial food made of freeze-dried and powdered algae of the same species. We found clear feeding preferences among the natural algae: the order of decreasing preference was F. vesiculosus $>$ Dictyosiphon foeniculaceus $>$ Elachista fucicola $>$ Pilayella littoralis $>$ Enteromorpha intestinalis > Ceramium tenuicorne. The preferences in the test with artificial food, however, did not parallel those with natural algae, suggesting that the chemical quality of algae is not the major determinant of feeding preferences. Furthermore, performance of isopods when reared on a diet of single algal species did not match the feeding preferences of natural algae: the most preferred brown alga provided poor growth rate. Surprisingly, the more phlorotannin a seaweed species contained, the more it was preferred by I. baltica. Moreover, the assimilation efficiency of soluble sugars was generally high when isopods fed on brown algae, and in the 2 species richest in phlorotannins it was not correlated with the phlorotannin concentration of the algal individual. In contrast to the conventional assumption of the defensive function of phlorotannins, this study shows that phlorotannins in seaweeds do not function as feeding deterrents to I. baltica. Instead, this herbivore readily feeds on phenolic-rich host plants, which, however, carries a cost in terms of decreased growth rate. We suggest that feeding preferences and habitat choice behavior evolve together; habitat structure, in terms of predation avoidance, and the spatiotemporal stability of the host algae are more important factors selecting for feeding preferences in mesoherbivores than the chemical composition of algae.
\end{abstract}

KEY WORDS: Specialization - Feeding preference - Herbivore performance - Phlorotannins · Herbivory $\cdot$ Fucus vesiculosus

\section{INTRODUCTION}

The feeding patterns of aquatic mesoherbivores are affected by both food quality and habitat value, but the relative importance of these factors is often difficult to assess. In general, herbivores are looking for energetic

*E-mail: veijo.jormalainen@utu.fi compounds and nutrients, such as proteins, nitrogen and carbohydrates, and the availability of these primary compounds is therefore expected to strongly affect food selection (Mattson 1980). However, plants may contain secondary compounds that either deter feeding or reduce the palatability of food. Such compounds are proposed to have evolved in the context of plant-herbivore interaction as a defense mechanism against herbivory (e.g. Feeny 1976, Rhoades 1979, Hay 
\& Fenical 1988), the benefit to the plant being its lower susceptibility for grazing.

Seaweeds contain secondary compounds that are considered to be mainly defenses against herbivores, although these substances may have a variety of other functions (Hay \& Fenical 1988, Paul 1992). Brown algae contain phenolic compounds - phlorotannins often in high concentrations (Targett \& Arnold 1998, Van Alstyne et al. 1999a,b). Phlorotannins have been shown to deter feeding by several herbivore species, especially echinoids and molluscs (reviewed by Targett \& Arnold 1998), but negative effects of phlorotannins have not always been found (Steinberg et al. 1991, Steinberg \& van Altena 1992, Pavia et al. 1997). Furthermore, phlorotannins reduce the assimilation efficiency of some herbivore species (Irelan \& Horn 1991, Boettcher \& Targett 1993), but not all of them (Targett et al. 1995). The effect of phlorotannins, or of phenolics in general, on the assimilation efficiency of herbivores is attributed mainly to their protein binding activity in the gut (Stern et al. 1996) and negative effects on digestive epithelia (Bernays et al. 1989). However, the action of phlorotannins is largely determined by the gut environment, e.g. the $\mathrm{pH}$ and the amount and quality of surfactants (Boettcher \& Targett 1993, Zimmer 1997). This led Targett et al. (1995) to suggest that differences in herbivore responses to phlorotannins may result from their diverse gut characteristics. While that may be the physiological explanation, an evolutionary explanation calls for an understanding of selection for resistance to phlorotannins.

Selection from upper trophic levels may strongly modify the food utilization patterns of mesoherbivores. In arthropod herbivores the value of the host plant as a habitat may affect differences in feeding patterns between potential host plants (e.g. Nicotri 1980, Hay et al. 1987, Hay 1992, Arrontes 1999). In a littoral habitat, visual predation by a variety of predatory fishes is usually high (e.g. Hay 1991, 1992, Arrontes 1999), and predation mortality is thus likely to be a major fitness component of mesoherbivores. In such a situation, habitat choice may override feeding preferences because it may be beneficial to trade off food quality with predation avoidance (e.g. Hay et al. 1987, Hay et al. 1989). When habitat choice dictates, food utilization evolves under this constraint. This may lead to adaptations in the digestive and metabolic characteristics of herbivores, allowing specialization in host plants of otherwise low quality. For example, a number of mesoherbivores use perennial brown algae, high in phlorotannin concentrations, for food (see Nicotri 1980, Pavia et al. 1999, Van Alstyne et al. 1999c).

Although adaptations may allow feeding on hosts that have high levels of secondary compounds, such feeding patterns may carry a cost in terms of growth rate or fecundity of the herbivore and, thus, a fitness trade-off between survival and growth may exist. The optimal solution to this trade-off may differ between the sexes of a herbivore. The fitness of males and females is, in general, composed differently by the components of fecundity and mating success. Often male fitness is highly dependent on the number of mates, while fecundity is the major component of female fitness (Bateman 1948, Arnold \& Duval 1994). The sexual differences in the relative importance of survival and growth for fitness may lead to different risk-taking, which may lead to sexual divergence of the feeding preferences and the ability to use different host species.

We quantified the feeding preferences and performance of a littoral isopod, Idotea baltica (Pallas), among the most common macroalgae in its habitat, separately for both the sexes. Specifically, we explored whether feeding preferences are explained by the chemical quality of algae. We tested this by comparing preferences observed among natural algae with those observed among artificial food made of the same species. Preferences observed in artificial food, where the morphologic structure of the algae is homogenized, should be due to chemical characteristics alone (Hay et al. 1998). We measured the quality of these algal species for the herbivore by determining its growth rate on each host species. We further compared the observed feeding preferences with the contents of both nutritive compounds (soluble and insoluble sugars, nitrogen) and the major secondary compounds (phlorotannins) of the algal species. In the 2 species with the highest phlorotannin concentrations, we tested whether within-species variation in phlorotannins affects assimilation efficiency.

\section{MATERIALS AND METHODS}

Organisms. Idotea baltica is a cosmopolitan isopod occurring in littoral macroalgal zones. It feeds on several brown, red and green algal species (Nicotri 1980). In the Baltic Sea this species is abundant in bladder wrack Fucus vesiculosus belts, and some feeding (Schaffelke et al. 1995) and habitat (Malm 1999) preferences of $F$. vesiculosus over other Fucus sp. have been found. It has a life span of about 12 to $15 \mathrm{mo}$; offspring are born in June, and growth occurs through winter to the next late spring when the breeding period starts (Salemaa 1979). The early instars feed mainly on filamentous algae, but from early autumn onwards they are found on $F$. vesiculosus. I. baltica uses F. vesiculosus as both food and habitat (Salemaa 1987), and it is able to grow and complete a molt cycle by feeding on bladder wrack 
alone (Jormalainen et al. 2001); the degree to which $I$. baltica has specialized to feeding on $F$. vesiculosus, however, is still unclear.

The isopod is a common prey for at least 17 fish species (Salemaa 1978), several of which are very abundant on our study area. Predation mortality is high as the densities decline continuously with the aging of the cohort (Jormalainen et al. 1995). For example, the evolution of cryptic coloration of this species has been attributed to selection by predation; crypsis is especially good on the background of Fucus vesiculosus (Salemaa 1978, Jormalainen et al. 1995).

In the northern Baltic Sea, Fucus vesiculosus is the major perennial algal species forming dense belts and thereby creating habitat structure. The typical algal assemblage of the $F$. vesiculosus zone in the northern Baltic consists of a number of species growing both as epibionts on Fucus and on surfaces below the bladder wrack canopy. Furthermore, annual species show typical seasonal dynamics, leading to temporally variable species composition. Thus Idotea baltica living in the $F$. vesiculosus belt face temporally variable food resources, with considerable potential for food choices. The feeding preferences of this herbivore species may have great importance for grazing pressure on littoral macroalgal species. During late summer and autumn, among the most abundant macro-algal species in the F. vesiculosus belts in our study area at the Archipelago Sea of Finland are 3 filamentous brown algae (Elachista fucicola, Dictyosiphon foeniculaceus and Pilayella littoralis), a filamentous red alga (Ceramium tenuicorne) and a green alga (Enteromorpha intestinalis). E. fucicola grows exclusively as an epiphyte on $F$. vesiculosus; $D$. foeniculaceus, $C$. tenuicorne, $P$. littoralis and $E$. intestinalis grow both as epiphytes on $F$. vesiculosus and on the bottom.

Feeding preference tests. We performed multiple choice feeding preference tests, in which Idotea baltica was allowed to choose among the 4 brown algae Fucus vesiculosus, Elachista fucicola, Dictyosiphon foeniculaceus and Pilayella littoralis, the red alga Ceramium tenuicorne and the green alga Enteromorpha intestinalis. We tested the preference of I. baltica among these algal species using both fresh algae and artificial agar-based food pellets made of powdered algae. For each of these preference tests we used 25 replicate choice situations for males and 25 for females. The artificial algal food was prepared by freeze-drying the fresh algae, grinding them and mixing the algal powder with a warm agar-water mixture (see Hay et al. 1998). The agar was allowed to solidify into lensshaped pellets. The dry weight content of the different algal species varied between 9 and $27 \%$; we simulated this between-species variation by using $0.9 \mathrm{~g} E$. intestinalis, $1.4 \mathrm{~g} F$. vesiculosus, $1.8 \mathrm{~g} D$. foeniculaceus, $2.0 \mathrm{~g}$
C. tenuicorne, $2.3 \mathrm{~g}$ E. fucicola and $2.7 \mathrm{~g}$ P. littoralis dry algal powder per $100 \mathrm{ml}$ water .

The experiment was started on September 2, 1999, with newly collected fresh algae, and on September 21, 1999, with artificial food. Each replicate experiment was conducted in a $1 \mathrm{l}$ plastic jar, containing a group of either 7 (natural algae) or 3 (artificial food) Idotea baltica of the same sex, and pieces of the 6 algae, either as fresh natural thallus or in agar-based pellets. The algae, or agar pellets, were dried between tissues, weighed (wet weight, $\pm 0.1 \mathrm{mg}$ ) and offered to the isopods. Feeding was allowed to take place for 4 (natural algae) or 3 (artificial pellets) days under $10^{\circ} \mathrm{C}$ and 10:14 h light:dark cycles, after which consumption was measured by reweighing the pieces.

To control for autogenous change in the weight of the algae, control jars without a herbivore were run for both fresh algae and agar pellets simultaneously under identical conditions as the herbivore jars. The consumption of each species was corrected for autogenous change following Manly's (1993) modification of the method by Roa (1992). In this procedure, consumption measures for each algal species from a herbivore jar are replaced with new values, calculated by subtracting the autogenous weight change of each species in a randomly chosen control jar from each measurement in a jar with herbivores. These values were then transformed into daily consumption per individual isopod.

We used nonparametric Friedman's 2-way analysis to test the $H_{0}$ hypothesis of no preference. This was performed separately for males and females in both food types. In order to test differences in the feeding preferences between the food types (natural versus artificial) and between the sexes we used a 2-way ANOVA of repeated measures; the consumptions of the 6 algae within a replicate trial formed the repeated measures, and food type and sex were treated as fixed factors. Such an analysis is an extension of the pairwise $t$-test for cases with more than 2 groups. We used the 'Procedure Mixed' in the SAS statistical package, because this procedure allows the heterogeneous variances to be taken into account by modeling the covariance structure of the repeated measures (Littell et al. 1996). Test results using unstructured covariance structure (Littell et al. 1996, p. 99) are shown; in our case the $F$-tests associated with the repeated measures are robust with respect to the modeled covariance structure. Normality of error variance was checked before accepting the analysis.

In order to test the association between feeding preferences and algal characteristics (see below) we performed an ordered heterogeneity test (Rice \& Gaines 1994). The $\mathrm{r}_{\mathrm{S}} \mathrm{P}_{\mathrm{C}}$ statistic, used to test the association between the order of preferences and speciesspecific algal characteristics, was obtained by combin- 
ing the probability from Friedman's test performed for preferences and the Spearman rank correlation coefficient between preference and algal characteristic.

Performance of Idotea baltica on different species of algae. Assimilation efficiency: Assimilation efficiency was estimated by a method using carbohydrate metabolism. In this method, assimilation is measured as a decrease in the ratio of soluble to insoluble sugars in the food and fecal pellets of the animal (method described in detail in Arrontes 1989). Since polysaccharides are a major constituent of seaweeds, and the digestibility of structural, insoluble polysaccharides by crustaceans is low (Arrontes 1989), this method gives a good approximation of assimilation efficiency. However, the method does not measure total assimilation but is strictly valid for sugar metabolism only.

For the assimilation measurements, we reared 20 males and 20 females individually on each of the 6 algal species in $1 \mathrm{l}$ jars $\left(10^{\circ} \mathrm{C}, 10: 14 \mathrm{~h}\right.$ light:dark cycle, aeration). The food algae were collected in such a way that each animal within a sex was fed with a different algal individual. Thus the variation found in the assimilation measurements incorporates both variation in algal quality and variation between Idotea individuals. Fecal pellets produced during the first $24 \mathrm{~h}$ were disregarded; the sample pellets for the assimilation measurements were collected during the next $2 \mathrm{~d}$, at $6 \mathrm{~h}$ intervals. The pellets were frozen immediately after collection and stored frozen until the quantification of soluble and insoluble sugars. Samples of food algae for the assimilation measurements were taken from the jars on the second day of rearing.

Differences in the assimilation efficiency between the algal species were tested separately for males and females, using the nonparametric Kruskal-Wallis test. After statistically significant Kruskal-Wallis tests, we performed all pairwise Mann-Whitney tests between the species. In order to keep the experiment-wise risk level at $\alpha=0.05$ we corrected the risk levels by the Bonferroni correction (Rice 1989). For these tests the sexes were pooled since the assimilation efficiency did not differ between the sexes within any of the species according to Mann-Whitney tests.

To test the effect of within-species variation in phlorotannin concentration on the assimilation efficiency of Idotea baltica, we chose 2 brown algae, Fucus vesiculosus and Dictyosiphon foeniculaceus, for further investigation. For these species, the phlorotannin concentration was determined (see below) for each individual food alga. Differences in assimilation efficiency between these 2 algal species and between sexes were analyzed by ANCOVA, with the possible effect of phlorotannin concentration of food included as a covariate (GLM procedure in SAS 6.12 package, SAS Institute 1990). Before proceeding to ANCOVA, the homogeneity of the slopes between the covariate and the dependent variable was tested, as well as the normality and homoscedasticity assumptions.

Growth performance: We started an experiment for measuring performance of Idotea baltica on the 6 species of algae on September 20, 2000. Animals belonging to the generation born in summer 2000 were collected from the field and maintained in individual containers in the laboratory. We checked the animals for the occurrence of the molt daily. Before the molt, animals were fed a large piece of Fucus vesiculosus and its epiphytic algae and a pellet of aquarium food. Right after the molt, the isopods were weighed (wet weight, $\pm 0.1 \mathrm{mg}$ ) and assigned randomly to 1 of the 6 diet groups; they were fed solely on 1 of the 6 algae used in the previous tests. Fifteen males and females were assigned to each feeding group. Algae were served in excess, and fresh algae were collected and changed weekly. The occurrence of the next molt was checked daily and when it was observed the individual was reweighed. The experiment was performed in $30 \mathrm{l}$ containers under $15^{\circ} \mathrm{C}$, aeration and 10:14 h light:dark cycle.

Weight gain, intermolt duration and growth rate, in terms of weight gain per intermolt duration, were calculated. The data were analyzed by a 2-way ANCOVA (weight gain, intermolt duration) or ANOVA (growth rate), with the algal species and the isopod sex as grouping factors and the initial weight as a covariate. The fulfillment of the normality, homoscedasticity and the homogeneity of slopes assumptions was checked before accepting the analyses. Duncan's a posteriori tests of differences between algal species in the growth rate were conducted within the sexes of Idotea baltica.

Measures of algal quality. The quality of plants for herbivores is determined not only by the contents of the supposed defensive compounds but to a great extent by their nutritive value. Secondary chemistry was studied by measuring the total content of phenolic compounds by a modification of the FolinCiocalteu method (Nurmi et al. 1996). Phloroglucinol was used as the reference compound. The FolinCiocalteu assay also quantifies nonphenolic hydroxylated aromatic compounds, but these make up $<5 \%$ of the total Folin-Ciocalteau-reactive compounds (Van Alstyne 1995). In the following, we use the term 'phlorotannins' for these total phenolics, since brown algae are known not to contain other polyphenolics and the other algae in this experiment showed nonsignificant amounts of phenols (Targett \& Arnold 1998). For Fucus vesiculosus and Dictyosiphon foeniculaceus we quantified a total of 20 samples of both species; for the others we made 3 replicate quantifications for each species. 
The nutritive value of algae was examined by determining contents of nitrogen, soluble and insoluble sugars, and the dry-weight content. Total contents of nitrogen and carbon were determined as a percentage of dry material by LECO CHN-900 carbon-hydrogennitrogen analyzer (LECO Corp., St. Joseph, MI). Three replicate samples for each species were quantified. To estimate the total amount of soluble and insoluble sugars in the thallus we used the spectrophotometric phenol sulfuric acid method (Arrontes 1989) and quantified the sugars in terms of absorbency per dry-weight unit. Three replicate samples for each species were determined.

All the chemical analyses were run from algal material, which was freeze-dried immediately after collection, and then finely ground stored at $-20^{\circ} \mathrm{C}$ until the final determination. Such a procedure is advised to preserve the chemical constituents in a best possible way (Waterman \& Mole 1994).

\section{RESULTS}

\section{Feeding patterns on fresh and powdered algae}

Idotea baltica showed clear feeding preferences in all tests conducted. In tests with natural algae, both males (Friedman's test: $\chi^{2}=84.5, \mathrm{df}=5, \mathrm{p}<0.001$ ) and females (Friedman's test: $\chi^{2}=64.2$, df $=5$, p < 0.001) preferred Fucus vesiculosus; the next preferred species were the 3 other brown algae (Fig. 1a,b). In the tests with artificial food, on the other hand, the preferences were completely changed (Fig. 1c,d): now Pilayella littoralis was the most preferred and $F$. vesiculosus the least preferred alga. The preference among the 6 algae in the test with artificial food was significant in both males (Friedman's test: $\chi^{2}=25.3$, df $=5, \mathrm{p}<0.001$ ) and females (Friedman's test: $\chi^{2}=$ $26.1, \mathrm{df}=5, \mathrm{p}<0.001)$. All significance levels reported remain the same after applying the experiment-wise Bonferroni adjustment.

The mean food consumption in tests with natural food was higher than that in the tests with artificial food; the males in particular ate more in the tests with natural food (Fig. 1, Table 1). Most interestingly, the food selection pattern differed significantly both between the 2 food types and between the sexes (Fig. 1, Table 1). The preferences were stronger in the tests with natural food than in those with artificial food (Fig. 1). Also, the preferences of males were slightly more pronounced than those of females.

\section{Performance on seaweed hosts}

The assimilation efficiency of Idotea baltica varied significantly among algal species in both males (Kruskal-Wallis test: $\chi^{2}=23.1$, df $=5, \mathrm{p}<0.001$ ) and females (Kruskal-Wallis test: $\chi^{2}=33.6$, df $=5, \mathrm{p}<$ 0.0001; Fig. 2). Assimilation efficiency was the best in
Fig. 1. Food consumption (mean $\pm \mathrm{SE}$ ) of Idotea baltica in a multiple choice experiment in which isopods were fed 6 species of fresh algae $(a, b)$ or artificial food made of the same algal species $(\mathrm{c}, \mathrm{d})$ separately for males $(\mathrm{a}, \mathrm{c})$ and females (b,d). C.t.: Ceramium tenuicorne; D.f. Dictyosiphon foeniculaceus; E.f.: Elachista fucicola; E.i.: Enteromorpha intestinalis; F.v.: Fucus vesiculosus; P.l.: Pila yella littoralis
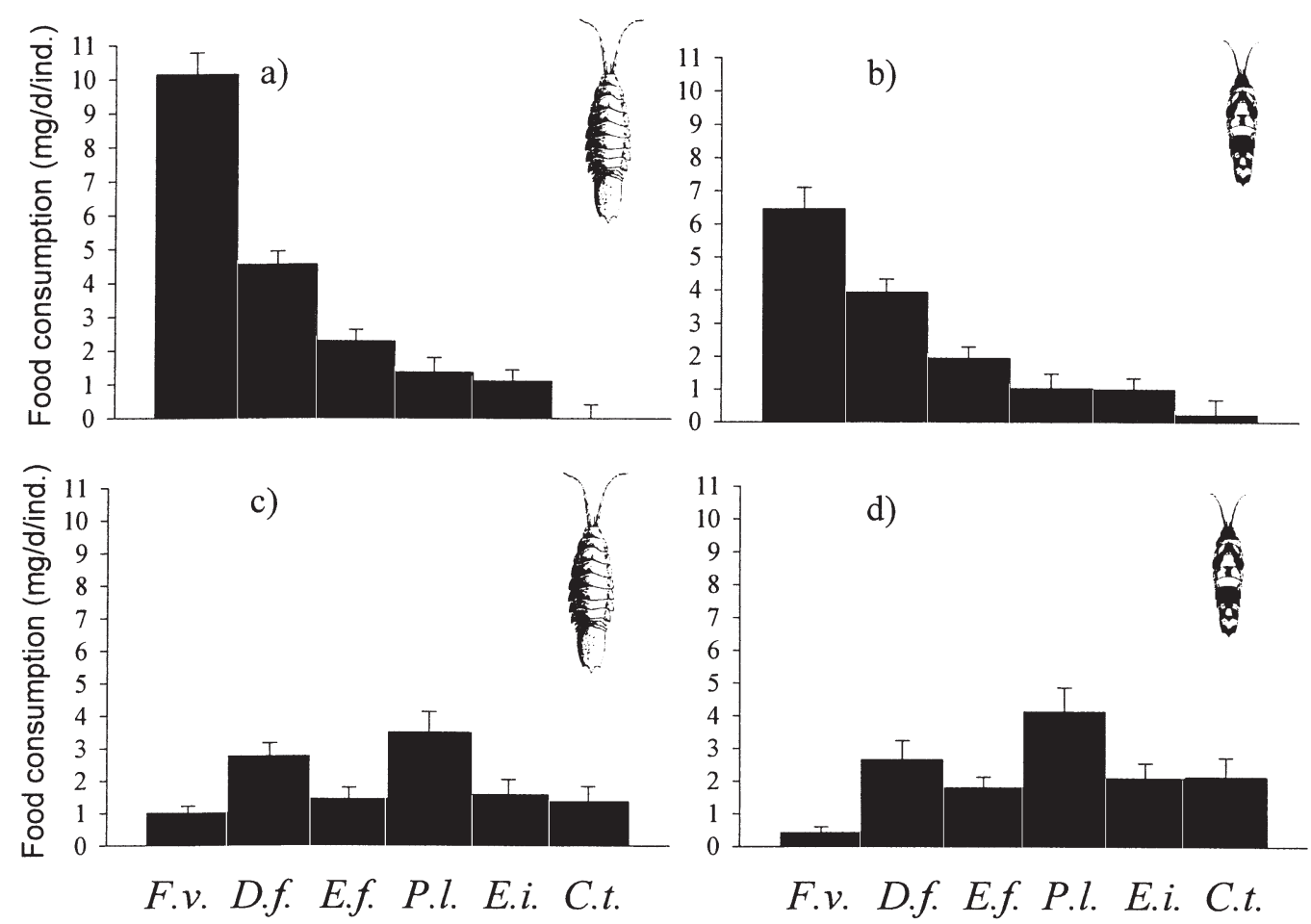
Table 1. Test statistics of a repeated measures ANOVA for the analysis of feeding preferences shown in Fig. 1. The consumption of each of the 6 algal species within a replicate were treated as repeated measures, and the food type (natural or artificial) and sex as fixed factors. Food type and isopod sex test for the differences in the average consumption, respectively, and algal species tests for the existence of a preference

\begin{tabular}{|lccc|}
\hline Source of variance & df & $F$ & $p$ \\
\hline Food type & 1 & 21.44 & $<0.0001$ \\
Isopod sex & 1 & 2.65 & 0.11 \\
Food type $\times$ Isopod sex & 1 & 10.6 & $<0.01$ \\
Algal species & 5 & 28.25 & $<0.0001$ \\
Algal species $\times$ Food type & 5 & 43.09 & $<0.0001$ \\
Algal species $\times$ Isopod sex & 5 & 2.67 & $<0.05$ \\
Algal species $\times$ Food type $\times$ & 5 & 0.64 & 0.67 \\
$\quad$ Isopod sex & & & \\
Error & 87 & & \\
\hline
\end{tabular}

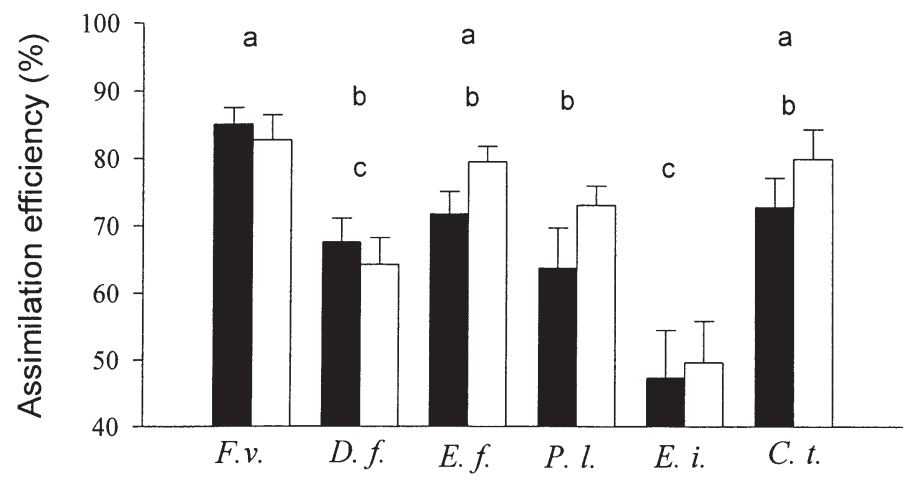

Fig. 2. Assimilation efficiency (mean $\pm \mathrm{SE}$ ) of Idotea baltica males (black bars) and females (white bars) on 6 species of algae. The pooled assimilation efficiency of the sexes does not differ between the algal species marked with the same letter; others differ at the experiment-wise $\alpha=0.05$ level according to the Bonferroni-adjusted, pairwise Mann-Whitney $U$-tests. See Fig. 1 for species abbreviations

Fucus vesiculosus, Elachista fucicola and Ceramium tenuicorne, and the worst in Enteromorpha intestinalis and Dictyosiphon foeniculaceus (Fig. 2).

In the test with the 2 species with high phlorotannin concentrations, the assimilation efficiency of Idotea baltica on Fucus vesiculosus, the species with the peak phlorotannin concentration, was significantly higher than that on Dictyosiphon foeniculaceus (Fig. 3, Table 2). The sexes did not differ in their assimilation efficiencies (Fig. 3, Table 2), nor was assimilation efficiency affected by the phlorotannin concentration of the algal individual of these phlorotannin-rich algae (Fig. 3, Table 2).

All the measures of the growth performance of Idotea baltica differed both between the algal species and between the sexes of the isopod (Fig. 4, Table 3). Both sexes gained weight best (Fig. 4a,b) and had the shortest intermolt duration (Fig. 4c,d) when feeding on Pilayella littoralis and Dictyosiphon foeniculaceus. Consequently, their growth rate was the best on these algae (Fig. 4e,f). The other 2 brown algae (Elachista fucicola and F. vesiculosus) were the next best and the red (Ceramium tenuicorne) and green (E. fucicola) algae the worst algal species for the growth performance (Fig. 4).

The weight gain of males was higher and their intermolt duration shorter than those of females (Fig. 4, Table 3). Interestingly, we also found a significant interaction of the isopod sex and algal species in the weight gain and growth rate, suggesting that the relative performance on different algal species varied between the sexes. In females, the variance of the performance between the host species was smaller than that in males.

\section{Relationships among algal characteristics, feeding preferences and performance}

Feeding preferences on natural algae were positively associated with concentrations of phlorotannins in the algae (Fig. 5a, Table 4) and negatively associated with the amount of insoluble sugars (Fig 5b, Table 4). Other algal characteristics measured did not correlate with preferences among natural algae (Table 4). Unexpectedly, nitrogen content tended to correlate negatively with preference; in particular, the red alga $C$. tenuicorne contained the highest nitrogen concentration but was not consumed at all (Fig 5b). It is also worth noting that within the 4 brown algae preferred, the preference declined with increasing drymass content (Fig 5c). In the artificial food, some algal characteristics were found to be associated with preferences at the $5 \%$ risk level, but none of them remained significant after application of the sequential Bonferroni correction (Table 4).

Table 2. ANCOVA test for differences in assimilation efficiency between sexes of Idotea baltica and between 2 algal species (Fucus vesiculosus and Dictyosiphon foeniculaceus). The effect of phlorotannin concentration was included as a covariate. Data shown in Fig. 3

\begin{tabular}{|lcrrc|}
\hline Source of variance & df & MS & $F$ & $\mathrm{p}$ \\
\hline Algal species & 1 & 3361.8 & 19.31 & $<0.0001$ \\
Isopod sex & 1 & 106.9 & 0.61 & 0.44 \\
Algal species $\times$ Isopod sex & 1 & 4.5 & 0.03 & 0.87 \\
Phlorotannin concentration & 1 & 76.4 & 0.44 & 0.51 \\
Error & 53 & 174.1 & & \\
\hline
\end{tabular}



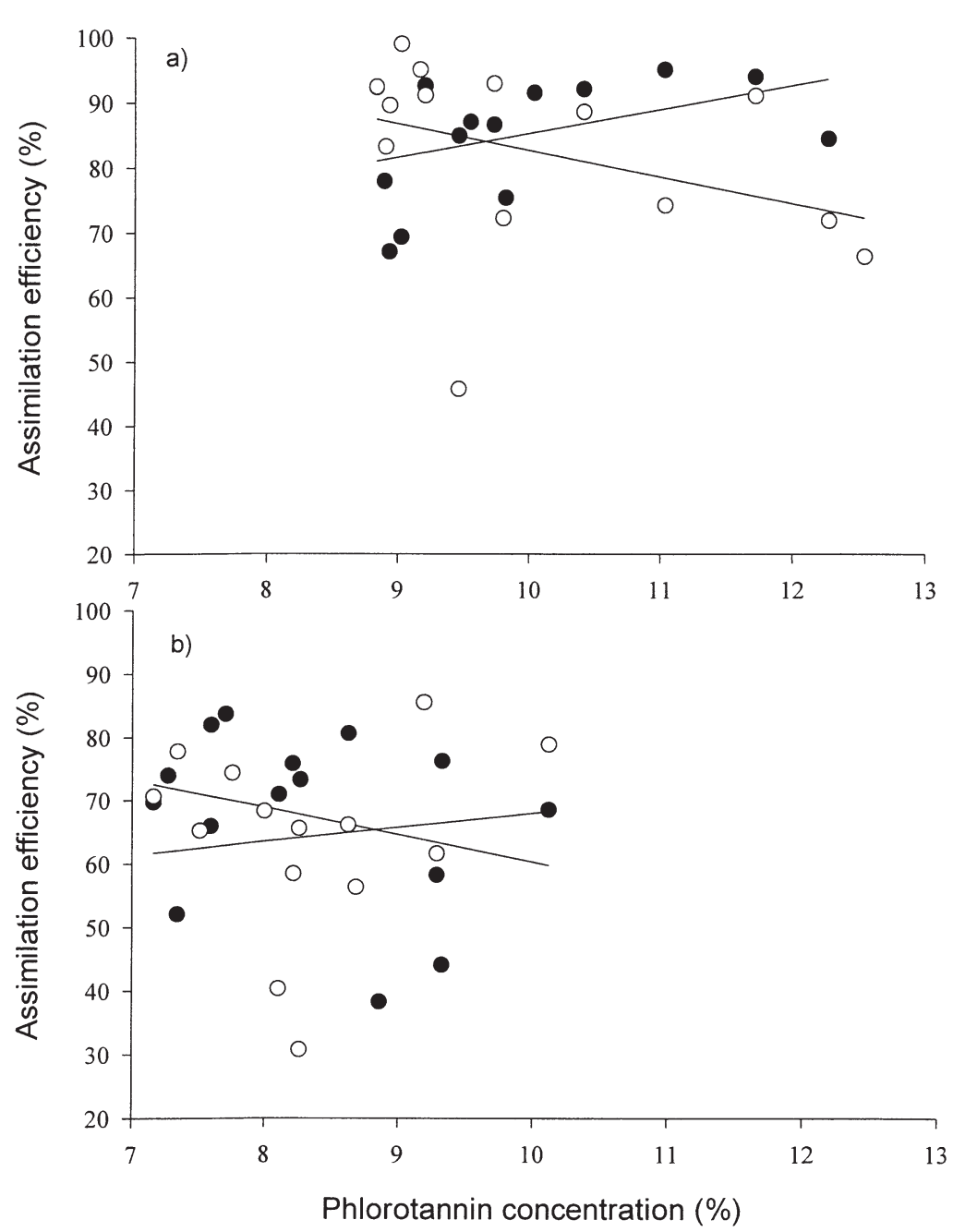

Fig. 3. Assimilation efficiency of Idotea baltica males (closed symbols) and females (open symbols) in relation to phlorotannin concentration of the algal individuals in (a) Fucus vesiculosus and (b) Dictyosiphon foeniculaceus

cant after the Bonferroni adjustment of risk levels for the number of correlations (variables listed in Table 4). Growth rate did not correlate significantly with any of the algal characteristics.

\section{DISCUSSION}

The chemical composition of the algae as such did not explain the feeding preferences of Idotea baltica. This conclusion follows from the finding that preferences with regard to natural algae were highly different from those in the case of the artificial food. Such a difference implies that feeding preferences are affected by external, nonchemical characteristics of algae. The lack of covariation of feeding preferences on natural hosts with the performance of this herbivore further supports this conclusion. We suggest that feeding behavior and habitat choices evolve together, and factors such as the value of hosts as a shelter and their temporal constancy may play an important role.

The comparison of feeding preferences with algal characteristics revealed no significant associations except the positive one with phlorotannins; this is consistent with the idea that feeding preferences are driven by factors other than algal chemistry. However, assimilation efficiency correlated positively with the amount of soluble sugars in the algae, suggesting that algae providing readily metabolizable sugars are a high-quality food for this herbivore. The

The feeding preference rank of natural algae did not match the rank of performance on them as the growth rate of Idotea baltica did not covary significantly with the feeding preferences (males: $\mathrm{r}_{\mathrm{S}} \mathrm{P}_{\mathrm{C}}=0.43$, not significant; females: $\mathrm{r}_{\mathrm{S}} \mathrm{P}_{\mathrm{C}}=0.43$, not significant). However, feeding preferences in the artificial food showed significant positive association with growth rate in both sexes (males: $r_{S} P_{C}=0.60, p<0.05$; females: $r_{S} P_{C}=0.54$, $\mathrm{p}<0.05)$. In the 4 brown algal species their order of feeding preferences and performance matched completely (Figs 1 \& 4).

We tested the effect of algal characteristics on assimilation efficiency and growth rate by correlation analysis. The amount of soluble sugars in each species correlated positively with the mean assimilation efficiency of the sexes $(r=0.94, \mathrm{df}=5, \mathrm{p}=0.005)$, and so did the concentration of carbon $(r=0.89, \mathrm{df}=5, \mathrm{p}=0.018)$. The former correlation was the only one to remain signifi- preference also tended to decrease with the increase of insoluble sugars; these are mostly structural polysaccharides that are not readily assimilated (Arrontes 1989). These findings hint at the potential role of polysaccharides in feeding preferences.

Most surprisingly, the feeding of this herbivore was not deterred by phlorotannins; on the contrary, the feeding preference order in the case of natural algae matched the order of increasing species-specific phlorotannin concentrations. Correspondingly, the assimilation efficiency of brown algae was generally high, and in the test with 2 high-phlorotannin algae we found no indication of a negative effect on assimilation efficiency of within-species variation in phlorotannin concentrations. This contradicts the conventional supposition that phlorotannins function mainly as feeding deterrents (Steinberg 1984, Hay \& Fenical 1988, Targett \& Arnold 1998, but see Steinberg \& van Altena 

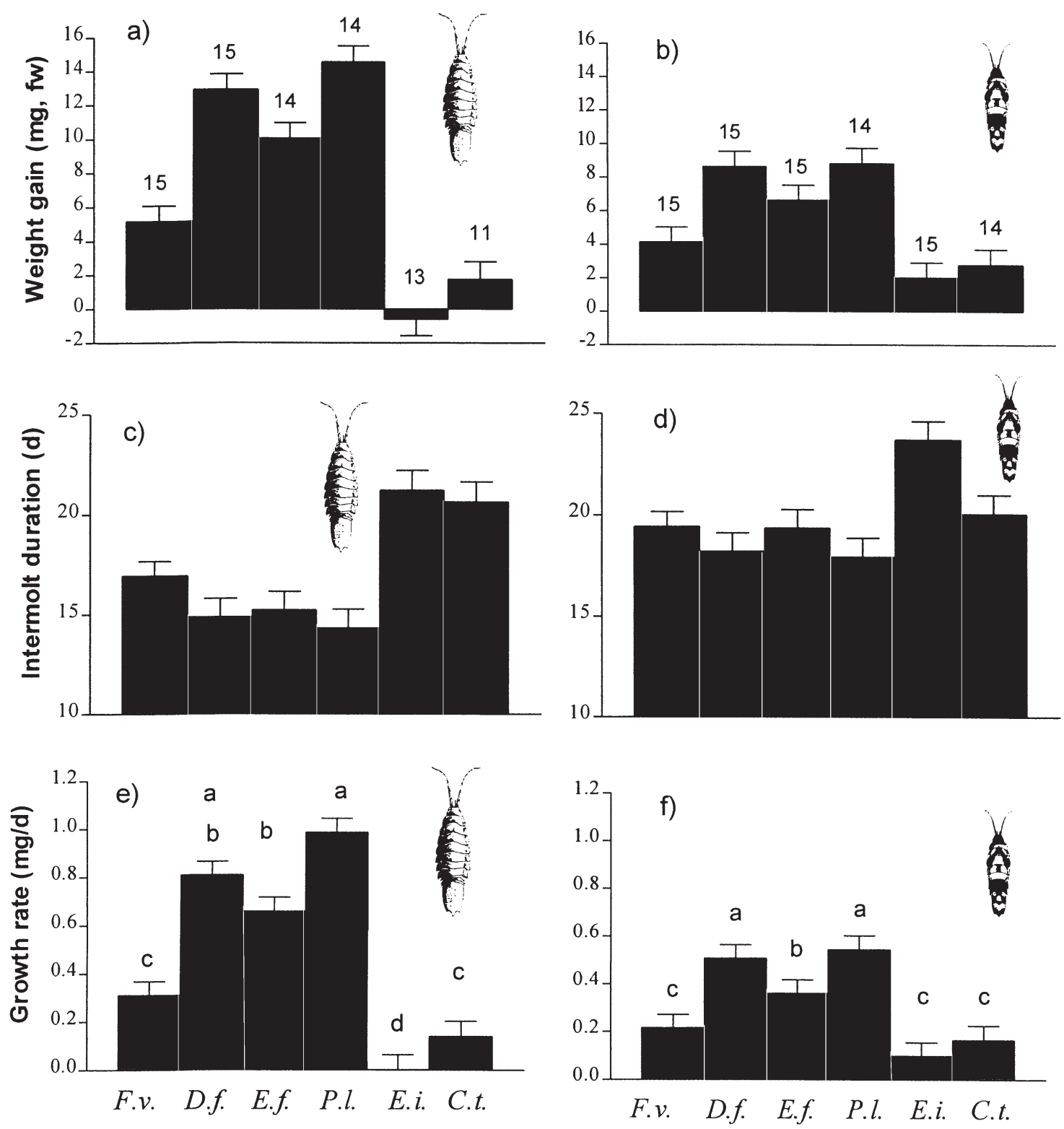

Fig. 4. Weight gain, intermolt duration and growth rate of male $(\mathrm{a}, \mathrm{c}, \mathrm{e})$ and female $(\mathrm{b}, \mathrm{d}, \mathrm{f})$ Idotea baltica reared on a single alga diet for the duration of 1 intermolt. In (e) and (f) separate letters differentiate the means differing at the $\alpha=0.05$ level according to Duncan's a posteriori test between means. See Fig. 1 for species abbreviations

Table 3. Analysis of growth performance (weight gain, intermolt duration and growth rate in terms of weight gain per intermolt day) of individuals reared on different algal species and of different sexes. Initial weight in the beginning of the experiment was used as a covariate in the analysis of weight gain and intermolt duration. Data shown in Fig. 4

\begin{tabular}{|c|c|c|c|c|c|c|c|c|c|c|c|c|}
\hline \multirow[t]{2}{*}{ Source of variance } & \multicolumn{4}{|c|}{ Weight gain } & \multicolumn{4}{|c|}{ Intermolt duration } & \multicolumn{4}{|c|}{ Growth rate } \\
\hline & $\mathrm{df}$ & MS & $F$ & $\mathrm{p}$ & df & MS & $F$ & $\mathrm{p}$ & $\mathrm{df}$ & MS & $F$ & $\mathrm{p}$ \\
\hline Algal species & 5 & 575.5 & 50.4 & $<0.001$ & 5 & 168.7 & 14.4 & $<0.001$ & 5 & 2.30 & 52.6 & $<0.001$ \\
\hline Isopod sex & 1 & 87.1 & 7.6 & $<0.01$ & 1 & 196.2 & 16.7 & $<0.001$ & 1 & 1.21 & 27.6 & $<0.001$ \\
\hline Algal species $\times$ Isopod sex & 5 & 72.7 & 6.4 & $<0.001$ & 5 & 19.3 & 1.6 & 0.15 & 5 & 0.32 & 7.0 & $<0.001$ \\
\hline Initial weight & 1 & 20.2 & 1.8 & 0.18 & 1 & 595.3 & 50.8 & $<0.001$ & & & & \\
\hline Error & 157 & 11.4 & & & 158 & 11.7 & & & 158 & 0.04 & & \\
\hline
\end{tabular}


Fig. 5. Feeding preferences (in percentage of total consumption) of natural algae in relation to (a) phlorotannin concentration, (b) amount of insoluble sugars, (c) nitrogen content and (d) dry-mass content of species. See Fig. 1 for species abbreviations
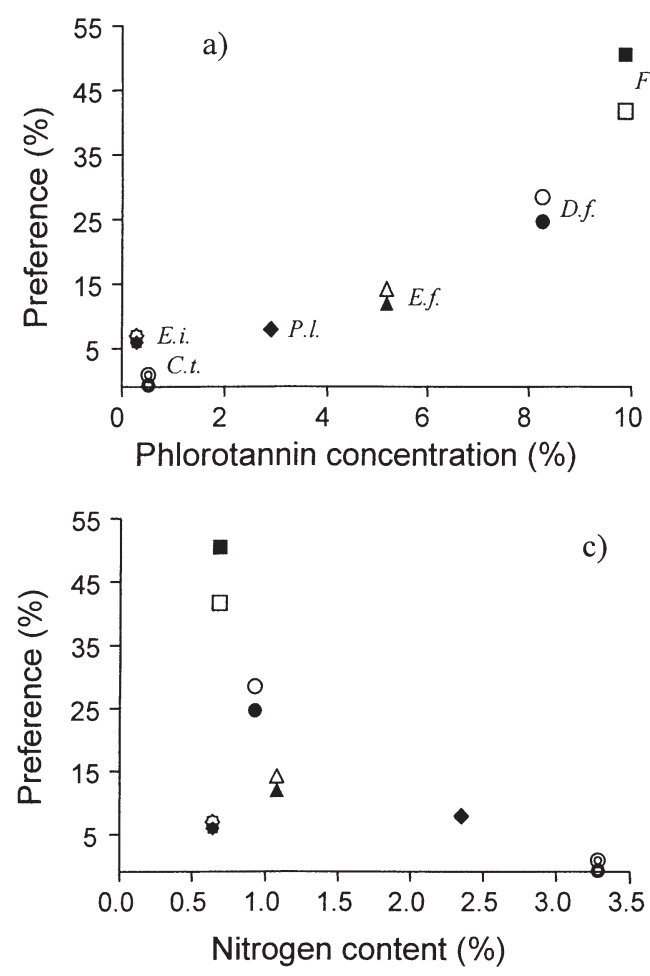
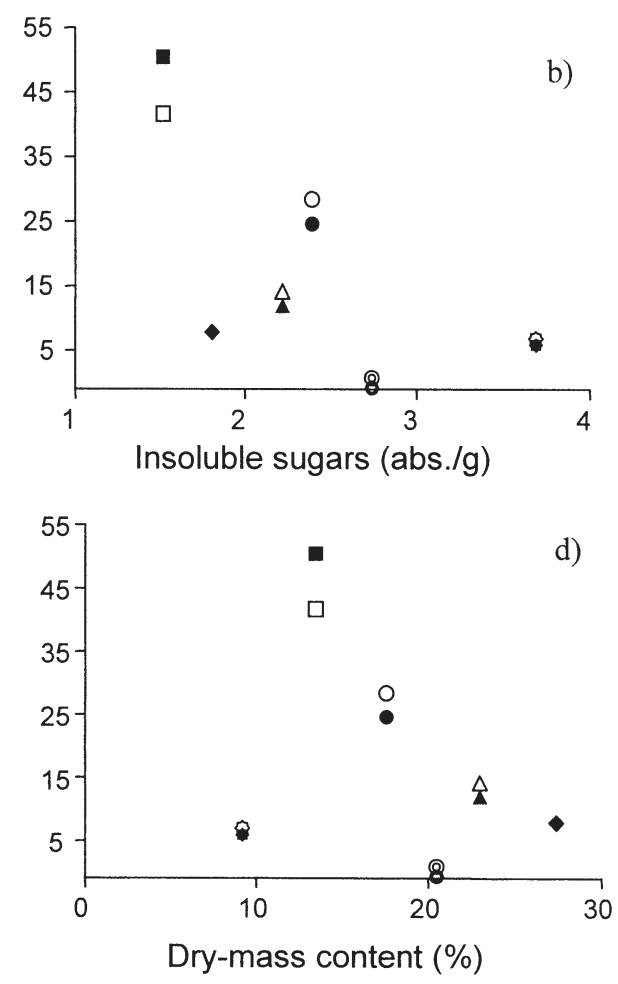

1992). The tolerance of Idotea baltica, and especially its feeding preference for brown algae, suggest that this herbivore has adapted so as to utilize phlorotannin-rich species.

Although the preference patterns of artificial food did not correlate significantly with any of the measured chemical characteristics of algae, there was a good match with herbivore performance: growth rate was the best on the most preferred species. Generally, the relation between feeding preference and performance on different hosts is poorly known in aquatic

Table 4. Association of concentrations of phlorotannins, nitrogen, carbon and sugars, and dry-mass content in algae with feeding preferences in natural and artificial food tested with ordered heterogeneity statistics. Sign of $\mathrm{r}_{\mathrm{S}} \mathrm{P}_{\mathrm{C}}$-statistics indicates direction of association. ${ }^{*}$ The only $\mathrm{p}$-value to remain significant at the $\alpha=0.05$ level after applying the table-wise sequential Bonferroni correction. NS: not significant

\begin{tabular}{|c|c|c|c|c|c|c|}
\hline \multirow[t]{3}{*}{ Algal characteristic } & \multirow{2}{*}{\multicolumn{2}{|c|}{$\begin{array}{c}\text { Preference of } \\
\text { natural algae, } \\
\text { Males and females }\end{array}$}} & \multicolumn{4}{|c|}{$\begin{array}{c}\text { Preference of } \\
\text { artificial food }\end{array}$} \\
\hline & & & \multicolumn{2}{|c|}{ Males } & \multicolumn{2}{|c|}{ Females } \\
\hline & $\mathrm{R}_{\mathrm{S}} \mathrm{P}_{\mathrm{C}}$ & $\mathrm{p}$ & $\mathrm{r}_{\mathrm{S}} \mathrm{P}_{\mathrm{C}}$ & $\mathrm{p}$ & $\mathrm{r}_{\mathrm{S}} \mathrm{P}_{\mathrm{C}}$ & $\mathrm{p}$ \\
\hline Phlorotannin & 0.942 & $<0.001^{*}$ & -0.257 & NS & -0.314 & NS \\
\hline Nitrogen & -0.428 & NS & 0.085 & NS & 0.486 & $<0.05$ \\
\hline Carbon & 0.143 & NS & -0.657 & $<0.05$ & -0.200 & NS \\
\hline Soluble sugars & 0.314 & NS & -0.599 & $<0.05$ & -0.548 & $<0.05$ \\
\hline Insoluble sugars & -0.714 & $<0.01$ & 0.143 & NS & 0.200 & NS \\
\hline Dry-mass content & -0.143 & NS & 0.371 & NS & 0.486 & $<0.05$ \\
\hline
\end{tabular}

mesograzers. In some amphipod species, habitat preference and performance have been found to correlate positively (Nicotri 1980, Poore \& Steinberg 1999), but this is not always the case (Duffy \& Hay 1991). A positive relation between preference and performance implies that intrinsic plant quality, i.e. nutritive contents and secondary chemistry, determines the host plant choice. Poore \& Steinberg (1999) found such a relation in the amphipod Peramphitoe parmerong; they could also attribute the preference-performance differences to the presence of nonpolar secondary metabolites. However, in the case of Idotea baltica the positive correlation of preference and performance only holds for artificial food, not for natural algae. This implies that feeding preferences and the ability to utilize the host for growth may have evolved together, but internal plant quality alone can not explain the choice of a host. The actual feeding pattern is adapted to external constraints.

M. E. Hay and others have suggested that predation avoidance of mesoherbivores may play a major role in their feeding specialization in chemically rich host algae (Hay et al. 1989, Hay et al. 1990, Duffy \& Hay 1991, Hay 1992). The rationale behind 
this hypothesis is that herbivorous generalist fishes form an important mortality factor for mesoherbivores. This leads to selection for habitat choice of predatorfree microhabitats. Algae, rich in secondary chemicals, efficiently deter herbivorous fishes (Paul \& Hay 1986, Hay et al. 1987, Van Alstyne \& Paul 1990), thus functioning as a predator refuge.

On the other hand, Estes \& Steinberg (1988) emphasize the importance of internal plant quality for feeding specialization. They suggested that marine herbivores adapt to compounds that are prevalent in common food plants because otherwise the avoidance of such host plants would exclude a major part of potential items from their diet. They hypothesized that, when herbivore populations are not regulated, or regulated only weakly, by predation, the tight coevolution of plant-herbivore interaction may lead to high phenolic concentrations in algae and high resistance to phenolics in herbivores (Estes \& Steinberg 1988, Steinberg et al. 1995). Evidence for this hypothesis is provided by comparative studies of phlorotannins and their deterrent effect across large geographical areas with dissimilar predation pressures on herbivores (Steinberg \& van Altena 1992, Steinberg et al. 1995).

Both these hypotheses suggest that the intensity of predation may strongly modify plant-herbivore interactions and may lead to feeding adaptations that otherwise would not be expected. In the case of Idotea baltica, however, the habitat specialization in phlorotannin-rich brown algae cannot be explained by their offering a refuge from herbivorous fishes. In the Baltic Sea there are no herbivorous fishes, and such species are also rare in northern temperate seas (Horn 1989). We suggest that the value of brown algae, especially Fucus vesiculosus, as a sheltered and stable habitat as such selects for adaptations to tolerate and utilize phlorotannin-rich food. In the Baltic, Fucus is the only large, perennial alga that creates a strongly 3 dimensional habitat structure. It provides temporal constancy and stability; this may be especially important in a highly seasonal environment, where the great majority of macroalgae are annual and have temporally and spatially highly dynamic distribution patterns. For example, all the algal species studied are available for I. baltica during late summer and autumn, but all other species except $F$. vesiculosus degenerate and disappear during the winter months, making feeding specialization in them unprofitable. Thus, seasonal variation in algal abundance is likely to interfere with the evolution of specialized feeding, as suggested by Duffy \& Hay (1991).

Interestingly, the most preferred natural food alga, Fucus vesiculosus, was among the poorest species in terms of growth rate of Idotea baltica attained on a single alga diet. Although the assimilation efficiency of soluble sugars on sole $F$. vesiculosus diet was among the best of the tested algae, I. baltica grew less when fed on this species than on the other 3 brown algae. This shows that habitat specialization to $F$. vesiculosus confers a fitness cost in terms of profitability of food. The phlorotannins may contribute to the low growth rate attained on $F$. vesiculosus, but the amount of total phlorotannins alone does not completely explain low profitability because Dictyosiphon foeniculaceus, which was among the best for performance, also had a high phlorotannin concentration. F. vesiculosus is poor or intermediate food for several amphipod herbivores (Cruz-Rivera \& Hay 2000), and Fucus sp. are low preference food for sea urchins and snails (Van Alstyne et al. 1999b).

The most preferred species after Fucus vesiculosus were the filamentous brown algae Dictyosiphon foeniculaceus, Elachista fucicola and Pilayella littoralis, which often grow on Fucus sp. as epiphytes. Thus Idotea baltica can feed on these species within the Fucus microhabitat. Furthermore, if $I$. baltica is already adapted to utilizing the high-phenolic Fucus sp., brown algae with lower phenolic levels may be readily digested and utilized as shown by the high growth rate attained on these species.

We found a slight but statistically significant sexual difference in both feeding preferences and performance on different algae of Idotea baltica. The order of preference was the same in both sexes, but females had a more even diet distribution than males. Accordingly, the performance of females showed smaller variability among the different host species. We suggest that this is related to sexual differences in the microhabitat choice patterns and consequent divergence of feeding adaptations of the sexes (Jormalainen et al. 2001). In habitat choice experiments within Fucus sp., females choose the older, basal parts more often than males (Merilaita \& Jormalainen 1997, 2000). The epiphytic brown algae, which were consumed proportionally more by females than by males, are most abundant in the older part of the thallus. Thus females encounter these species more often than males and use them as food.

Perennial brown algae are usually the major habitat component of the littoral environment, thereby providing shelter. Habitat choice of such seaweeds makes feeding specialization in these phlorotannin-rich algae beneficial, since mobility among microhabitats is likely to be both costly and risky. Feeding specialization in a habitat-forming species has no search cost, which would otherwise oppose the evolution of specialization; such a cost would be present if the species specializes in other species or maintains a diverse diet. Therefore the conditions for feeding specialization in a habitat-forming species are even more favorable than 
usually considered (Fry 1996). Such specialization may well lead to intense coevolutionary plant-herbivore interaction, resulting in high concentrations of feeding deterrents and herbivores with a high resistance to these compounds. However, our data show that costs may arise in terms of lower profitability of food, implying that food quality may at least to some extent control growth of such a herbivore population. We suggest that it is predation, not its absence, that here acts as a catalyst in the keen interaction between plant and herbivore (cf. Steinberg et al. 1995).

Acknowledgements. We thank the Archipelago Research Institute of the University of Turku for providing facilities, Roosa Leimu and Jenni Korhonen for help in the experiments, and Johanna Oja for quantifying phlorotannins. The study was financed by the Academy of Finland (Project 44086).

\section{LITERATURE CITED}

Arnold SJ, Duvall D (1994) Animal mating systems: a synthesis based on selection theory. Am Nat 143:317-348

Arrontes J (1989) A new method for estimating digestive efficiency in herbivorous crustaceans. Comp Biochem Physiol 94A:133-136

Arrontes J (1999) On the evolution of interactions between marine mesoherbivores and algae. Bot Mar 42:137-155

Bateman AJ (1948) Intra-sexual selection in Drosophila. Heredity 2:349-368

Bernays EA, Cooper Driver G, Bilgener M (1989) Herbivores and plant tannins. Adv Ecol Res 19:263-302

Boettcher AA, Targett NM (1993) Role of polyphenolic molecular size in reduction of assimilation efficiency in Xiphister mucosus. Ecology 74:891-903

Cruz-Rivera E, Hay ME (2000) The effects of diet mixing on consumer fitness: macroalgae, epiphytes, and animal matter as food for marine amphipods. Oecologia 123:252-264

Duffy JE, Hay ME (1991) Food and shelter as determinants of food choice by an herbivorous marine amphipod. Ecology 72:1286-1298

Estes JA, Steinberg PD (1988) Predation, herbivory, and kelp evolution. Paleobiology 14:19-36

Feeny P (1976) Plant apparency and chemical defense. Recent Adv Phytochem 10:1-40

Fry JD (1996) The evolution of host specialization: are tradeoffs overrated? Am Nat 148:S84-S107

Hay ME (1991) Marine-terrestrial contrasts in the ecology of plant chemical defences against herbivores. Trends Ecol Evol 6:362-365

Hay ME (1992) The role of seaweed chemical defenses in the evolution of feeding specialization and in the mediation of complex interactions. In: Paul VJ (ed) Ecological roles of marine natural products. Cornell University Press, Ithaca, p 93-118

Hay ME, Fenical W (1988) Marine plant-herbivore interactions: the ecology of chemical defence. Annu Rev Ecol Syst 19:111-145

Hay ME, Duffy JE, Pfister CA, Fenical W (1987) Chemical defense against different marine herbivores: are amphipods insect equivalents? Ecology 68:1567-1580

Hay ME, Pawlik JR, Duffy JE, Fenical W (1989) Seaweedherbivore-predator interactions: host plant specialization reduces predation on small herbivores. Oecologia 81:418-427
Hay ME, Duffy JE, Fenical W (1990) Host-plant specialization decreases predation on a marine amphipod: an herbivore in plant's clothing. Ecology 71:733-743

Hay ME, Stachowicz JJ, Cruz-Rivera E, Bullard S, Deal MS, Lindquist N (1998) Bioassays with marine and freshwater macroorganisms. In: Haynes KF, Millar JG (eds) Methods in chemical ecology. Kluwer Academic Publishers, Norwell, p 39-141

Horn MH (1989) Biology of marine herbivorous fishes. Oceanogr Mar Biol Annu Rev 27:167-272

Irelan CD, Horn MH (1991) Effects of macrophyte secondary chemicals on food choice and digestive efficiency of Cebidichthys violaceus (Girard), an herbivorous fish of temperate marine waters. J Exp Mar Biol Ecol 153: 179-194

Jormalainen V, Merilaita S, Tuomi J (1995) Differential predation on sexes affects colour polymorphism of the isopod Idotea baltica (Pallas). Biol J Linn Soc 55:45-68

Jormalainen V, Honkanen T, Hemmi A, Mäkinen A, Vesakoski O (2001) Why does herbivore sex matter? Sexual differences in utilization of Fucus vesiculosus by the isopod Idotea baltica. Oikos 93:77-86

Littell RC, Milliken GA, Stroup WW, Wolfinger RD (1996) $\mathrm{SAS}^{\circledR}$ system for mixed models, 3rd edn. SAS Institute Inc. Cary

Malm T (1999) Distribution patterns and ecology of Fucus serratus L. and Fucus vesiculosus L. in the Baltic Sea. PhD thesis, University of Stockholm

Manly BFJ (1993) Comments on design and analysis of multiple-choice feeding-preference experiments. Oecologia 93:149-152

Mattson WJ (1980) Herbivory in relation to plant nitrogen content. Annu Rev Ecol Syst 11:119-161

Merilaita S, Jormalainen V (1997) Evolution of sex differences in microhabitat choice and colour polymorphism in Idotea baltica. Anim Behav 54:769-778

Merilaita S, Jormalainen V (2000) Different roles of feeding and protection in diel microhabitat choice of sexes in Idotea baltica. Oecologia 122:445-451

Nicotri ME (1980) Factors involved in herbivore food preference. J Exp Mar Biol Ecol 42:13-26

Nurmi K, Ossipov V, Haukioja E, Pihlaja K (1996) Variation of the total phenolic content and individual lowmolecular-weight phenolics in foliage of mountain birch trees (Betula pubescens ssp. tortuosa). J Chem Ecol 22: 2023-2040

Paul VJ (1992) Seaweed chemical defenses on coral reefs. In: Paul VJ (ed) Ecological roles of marine natural products. Cornell University Press, Ithaca, p 24-50

Paul VJ, Hay ME (1986) Seaweed susceptibility to herbivory: chemical and morphological correlates. Mar Ecol Prog Ser 33:255-264

Pavia H, Cervin G, Lindgren A, Åberg P (1997) Effects of UV$\mathrm{B}$ radiation and simulated herbivory on phlorotannins in the brown alga Ascophyllum nodosum. Mar Ecol Prog Ser 157:139-146

Pavia H, Carr H, Åberg P (1999) Habitat and feeding preferences of crustacean mesoherbivores inhabiting the brown seaweed Ascophyllum nodosum (L.) Le Jol. and its epiphytic macroalgae. J Exp Mar Biol Ecol 236:15-32

Poore AGB, Steinberg PD (1999) Preference-performance relationships and effects of host plant choice in an herbivorous marine amphipod. Ecol Monogr 69:443-464

Rhoades DF (1979) Evolution of plant chemical defense against herbivores. In: Rosenthal DA, Janzen DH (eds) Herbivores: their interaction with secondary plant metabolites. Academic Press, New York, p 3-54 
Rice WR (1989) Analysing tables of statistical tests. Evolution 43:223-225

Rice WR, Gaines SD (1994) Extending nondirectional heterogeneity tests to evaluate simply ordered alternative hypotheses. Proc Nat Acad Sci USA 91:225-226

Roa R (1992) Design and analysis of multiple-choice feedingpreference experiments. Oecologia 89:509-515

Salemaa H (1978) Geographical variability in the colour polymorphism of Idotea baltica (Isopoda) in the northern Baltic. Hereditas 88:165-182

Salemaa H (1979) Ecology of Idotea spp. (Isopoda) in the northern Baltic. Ophelia 18:133-150

Salemaa H (1987) Herbivory and microhabitat preferences of Idotea spp. (Isopoda) in the northern Baltic Sea. Ophelia 27:1-15

SAS Institute (1990) SAS user's guide: statistics. SAS Institute Inc., Cary

Schaffelke B, Evers D, Walhorn A (1995) Selective grazing of the isopod Idotea baltica between Fucus evanescens and F. vesiculosus from Kiel Fjord (western Baltic). Mar Biol 124:215-218

Steinberg PD (1984) Algal chemical defense against herbivores: allocation of phenolic compounds in the kelp Alaria marginata. Science 223:405-406

Steinberg PD, Van Altena IA (1992) Tolerance of marine invertebrate herbivores to brown algal phlorotannins in temperate Australasia. Ecol Monogr 62:189-222

Steinberg PD, Edyvane K, de Nys R, Birdsey R, Van Altena IA (1991) Lack of avoidance of phenolic-rich brown algae by tropical herbivorous fishes. Mar Biol 109:335-343

Steinberg PD, Estes JA, Winter FC (1995) Evolutionary consequences of food chain length in kelp forest communities. Proc Nat Acad Sci USA 92:8145-8148

Editorial responsibility: Joseph Pawlik (Contributing Editor), Wilmington, North Carolina, USA
Stern JL, Hagerman AE, Steinberg PD, Mason PK (1996) Phlorotannin-protein interactions. J Chem Ecol 22: 1877-1899

Targett NM, Arnold TM (1998) Predicting the effects of brown algal phlorotannins on marine herbivores in tropical and temperate oceans. J Phycol 34:195-205

Targett NM, Boettcher AA, Targett TE, Vrolijk NH (1995) Tropical marine herbivore assimilation of phenolic rich plants. Oecologia 103:170-179

Van Alstyne KL (1995) The comparison of three methods for quantifying brown algal polyphenolic compounds. J Chem Ecol 21:45-58

Van Alstyne KL, Paul VJ (1990) The biogeography of polyphenolic compounds in marine macroalgae: temperate brown algal defenses deter feeding by tropical herbivorous fishes. Oecologia 84:158-163

Van Alstyne KL, Ehlig JM, Whitman SL (1999a) Feeding preferences for juvenile and adult algae depend on algal stage and herbivore species. Mar Ecol Prog Ser 180: 179-185

Van Alstyne KL, McCarthy III JJ, Hustead CL, Duggins DO (1999b) Geographic variation in polyphenolic levels of Northeastern Pacific kelps and rockweeds. Mar Biol 133: 371-379

Van Alstyne KL, McCarthy III JJ, Hustead CL, Kearns LJ (1999c) Pholorotannin allocation among tissues of Northeastern Pacific kelps and rockweeds. J Phycol 35: 483-492

Waterman PG, Mole S (1994) Analysis of phenolic plant metabolites. Blackwell Scientific Publications, Oxford

Zimmer M (1997) Surfactants in the gut fluids of Porcellio scaber (Isopoda: Oniscidea), and their interactions with phenolics. J Insect Physiol 43:1009-1014

Submitted: September 22, 2000; Accepted: January 17, 2001 Proofs received from author(s): August 29, 2001 